CHAPTER

\title{
The Murder Next Door
}

Developing healing responses and building community following trauma using research-based theatre

\author{
Rosemary C. Reilly \\ Concordia University, Montréal
}

Traumatic events involving murder profoundly affect community residents and their relationships with their families and neighbours. Appropriate responses to such trauma typically include providing individual therapy, but trauma is also a collective experience.

Community-level trauma damages the basic tissue of social life, rupturing the bonds that attach people to each other and involves a shocking and gradual realisation that the community is no longer an effective source of support (Erikson, 1976). This results in a loss of interpersonal connection, a pervasive sense of sorrow and purposelessness, disorientation, low community morale, and a loss of community identity (Raphael, 1986).

Little attention is given to local initiatives that address nonclinical healing of the community as a whole. Trauma may decrease or increase a community's sense of communality, the cohesive threads that bind a community together and create an environment in which individuals can lead enriching lives. Research highlights that how a community responds post-trauma can make the difference between members experiencing posttraumatic stress which leads to relationships becoming antagonistic, fractured, and alienated (see Reilly, 2011) or posttraumatic growth which is the positive psychological change that results from the successful struggle with challenging life circumstances. Posttraumatic growth is not about returning to the same life one lived prior to the trauma but is, rather, about undergoing significant shifts in thinking and relating to the world that contribute to a process of deeply meaningful change (Calhoun \& Tedeschi, 2006).

Collective trauma must be transformed in and by the community. Since mutual social support forms the foundation for psychologically rebuilding community, relationships with family, co-workers, and neighbours become a primary source of recovery and healing. This allows communities not only to bounce back, but to "bounce forward" 
as Manyena et al. (2011) have indicated in the title of their article and move from a sense of powerlessness towards pride and deep-rooted attachment. Most communities have outlined plans to deal with natural disasters and emergencies, but municipal officials and community leaders have little guidance on how to address psychological or emotional community trauma and its aftermath. When trauma strikes, it affects everyone. It is not uncommon for residents to feel less positive, less energetic, and unable to enjoy life in the aftershock of a trauma; they are less able to generate and implement healing strategies themselves. Therefore, it is imperative that strategies for local community healing be identified prior to the occurrence of trauma. The project I discuss in this chapter created an opportunity for community members to engage in just such strategies. Using principles of researchbased theatre (Belliveau, 2015) I created a readers' theatre presentation about the murder of a family in a close-knit small town. I theatricalised research data gleaned from three case studies of community trauma in an urban community (two domestic homicides), a rural one (the murder of a young girl), and a school community (a mass shooting). This performance functioned as a starting point for discussions on how to promote community healing effectively outside of an existing real-life trauma and its emotional and psychological wake.

\section{Research-Based Theatre}

Theatre is increasingly employed as a method and methodology in scholarly settings. It has been validated as a tool to critically and effectively collect and analyse data, educate audiences about significant issues, enliven and enrich the dissemination of research findings, shape public policy, advance social change by engaging and addressing issues of social justice, oppression, and marginalisation, and intervene in human systems, promoting attitude and behaviour change. ${ }^{1}$ Theatre has the ability to capture and communicate complicated knowledge about multifaceted social realities and relationships in ways that affect the heart and mind in connecting the audience personally to the genuine experiences portrayed in the performance. When they are theatricalising data, researchers show, not tell, the results of their research, thus creating three-dimensional portraits of their data. These portraits allow "one to retain, at least somewhat, the human dimensions of the life experience qualitative research attempts to study ... to not lose research participants in the data or not transform them into 
dehumanized stereotypes" (Donmoyer \& Donmoyer, 2008, p. 216). Research-based theatre has taken on many forms from verbatim theatre to performance ethnography and from documentary theatre to ethnodrama (Belliveau, 2015).

\section{Readers' Theatre}

Readers' theater is a sub-genre in which actors hold scripts, staging is simplified, scenery is limited to stools and ladders, and costumes, if used at all, are little more than articles of clothing intended to suggest, rather than represent, a character (Donmoyer \& Donmoyer, 2008). I chose this format for my research-based drama since it is, by design, a stylised rather than a realistic form; readers' theatre is presentational rather than representational. Whereas representational forms attempt realism, presentational forms ask audience members to fill in what has been intentionally omitted onstage and, in the process, co-construct with the actors the meaning of the work. In my theatre project, this created the optimal amount of aesthetic distance (Bleuer at al., 2018)-a space between an overly emotional state regarding the murder of a woman and her young children, and the overly rational state of typical research objectivity. This aesthetic distance allowed audience members to use all their intellectual and emotional resources to develop empathic and perceptive responses regarding beneficial community healing strategies.

\section{Playwriting}

Saldaña (1998) has noted that ethnotheatre has inherent ethical issues regarding the presentation of participants' experiences. Exposing intimate conflicts, distorting personal histories, and violating privacy; in essence, the so-called juicy stuff that fuels good storytelling may, in fact, challenge the researcher's ethical obligation to do no harm. This was my primary concern since I had witnessed the effects of the stigma attached to communities and their members during the aftermath of a murder. Therefore, rather than presenting the findings from one case, I drew on the themes that emerged from the three separate ones mentioned above, and created a fictitious amalgamation of events, characters, situations, and interactions. Since the purpose of the performance was to create a context in which to generate healing strategies, the events of the play unfold following the murder which is never depicted in the play but is only referenced. I focused on those themes that, generally, are 
unnoticed to emphasise the hidden impact of them on community members. For example (see the scene below), I highlight the internal conflicts felt by the owner of the house where the murder had occurred, and show how this impacted him personally and economically. In the play, I cycle back-and-forth between verbatim presentations of the data in the form of monologues (to lend veracity and authenticity) to imagined, private interactions that expose the more painful effects of this community trauma. The play lasts approximately 50 minutes and uses a structure similar to that of The Laramie Project (Kaufman, 2001).

\section{An Excerpt from The Murder Next Door}

\section{ACT [1] SCENE [1]}

The scene is a cramped real estate office. There is a desk, a telephone, and some piles of paper-neat but busy. Chuck Branden is seated; he is writing and examining some files. After a few moments, he glances up, as if realizing that someone else has come into the office.

\section{CHUCK}

I have lived in Lawton my whole life. It's the sense of community that keeps us here. So, do I think it's changed since the murders? Obviously, there was the horror and the shock ... Oh, and the media, of course.

(Sigh)

But has it changed us?

There were the piles of teddy bears and ceramic angels, and candles. And tons of flowers on the porch of the house. The folks over at the Kiwanis put together a trust fund for Kevin. He survived only because he wasn't home at the time. So, when he's ready to leave his aunt's place, to live on his own or go to college or whatever, he'll have something. And the school where Jamie and Michelle went, they planted a tree. It's all about dealing with the hurt, if that makes sense.

Me?

\section{(Pause)}

As the owner, I just had to be practical, but I tried to be human about it. That started the moment I met the Martins, ah ... Joanne's parents. There was no way that they could go into that house. That made all sorts of sense to me. Okay fine, I'll be the go-between. So I asked them, "What do you want? What sorts of things are important to you?" So they made a list. Sentimental stuff, mostly. We searched the house high and low for 
everything we could, and eventually, I think we found everything on the list. Well, actually ... I don't know if we ever found Joanne's wedding ring.

(Pause)

The hardest part?

(Pause)

I suppose it was the time right after it happened. I first went into the house after the police had taken ... whatever evidence they needed. It wasn't pleasant to deal with physically. My business partner, Jim, and I ripped everything apart, right down to the ground. All the carpets out and new carpets put in. All the walls, completely scrubbed down and disinfected. We repainted everything. It was the only way you could deal with it. Because, we had to re-rent it.

(Pause)

I guess, one of the twinges of guilt I felt throughout this whole thing was about Mr. Martin, and how he felt. He would have loved to see the house just demolished. As a dad, I could relate to that. That's what I found hard: Chuck the human being versus Chuck the landlord. We just didn't have a choice. Maybe if we did, we might have bulldozed the whole thing.

(Pause)

There's still a stigma attached to that house. One of the guys who moved in afterwards had a priest come in to bless the house, I guess, or whatever they wanted.

(Pause)

So, do I think Lawton's changed? I'm not sure.

(Blackout)

This scene sets out the question, "Has this trauma changed this closeknit community?" The readers' theatre performance attempts to demonstrate how.

\section{Readers' Theatre Performance as Data Collection}

\section{Method}

A focus group methodology was used during the post-performance discussions to create a reflective and collaborative problem-solving space. Since focus groups are a socially-oriented technique for capturing 
data (Krueger \& Casey, 2009), this was the best method to elicit the audience's perceptions, feelings, attitudes, and ideas concerning the themes of the research, provide the ground for understanding the impact on the community, and afford an interactive, dynamic source of data regarding strategies for fostering community healing. The postperformance discussions lasted approximately 45 minutes. Attendees were divided into groups of four to five to maximise their airtime. One simple question was posed: "If you were a member of this community, what would be some of the strategies you would find beneficial and effective to help the community to heal itself?"

\section{Setting and Participants}

The readers' theatre script was piloted twice on two different university campuses to test its effectiveness. Participants were recruited by open invitation through an advertisement linked to a research seminar, and a full description of the theatre presentation was included. No preparation was required. Although both pilots were with academic researchers and university students older than 18 , audience members were encouraged to approach this experience as a person who lived in a neighbourhood where this might occur. In total, 45 participants attended the pilot performances and the post-performance discussions.

\section{Data Collection and Analysis}

Data was collected on flipchart paper during the focus groups by a facilitator who recorded the contributions of the participants and by participants who were also encouraged to record their own thoughts and suggestions. In this way, all data was anonymised in an aggregate form. The data was analysed using the constant comparative method, a systematic inductive process used for categorising and comparing qualitative data.

\section{Ethical Considerations}

Research ethics approval was obtained from the University Human Research Ethics Committee. Strategies for minimising potential harm to research participants included a poster outside the performance space alerting audience members to the focus of the play and its allusion to murder (although the exposure to violent content was far less than is the case in the average TV show). This caveat was repeated from the 
stage area prior to the performance and reiterated before the postperformance discussion. I also emphasised that anyone could leave the performance space at any time, or choose to remain but not voice comments during the discussion. A short break followed the performance to allow audience members to leave inconspicuously. The verbal consent script stressed that if audience members remained, this implied their consent to participate. A sheet with psychological resources was also provided.

\section{Findings from the Performances}

At both performances, all audience members stayed for the postperformance discussion, which was lively and varied. Participants engaged conceptually with the piece by offering a range of informed, diverse opinions on policy issues and possible solutions for community healing. Additionally, participants engaged emotionally by disclosing and discussing what this might mean if it occurred in their own communities.

Beneficial strategies for healing generated in the focus group discussions tended to gather around five main themes outlined below.

\section{Acknowledgement of Community Trauma as a Civic Responsibility}

Building on the idea that every community has an emergency preparedness plan, participants suggested, as a proactive response, that a community trauma team be struck as a regular feature of municipal services. This team would be knowledgeable about community trauma, and trained in various aspects of community-building post-trauma. It then could be activated when needed. As well, participants noted that plans for responding to community trauma needed to be considered as a long-term (at least a year) investment that would be developed in phases and be responsive to the unique needs of the community.

A crucial first step many participants advanced was the public acknowledgement by local officials and leaders that this was a community issue and responsibility. Addressing the stigma and isolation that trauma activates would be a necessary precondition that would then allow community members to access and participate in other initiatives. This would be achieved not only in words, but also in actions. Local officials (and the trauma team, if in place) would co-ordinate the dissemination of accurate information (to combat gossip and rumours) 
through a community bulletin and/or website. This channel of information would also have an up-to-date resource list that people could access for various support services, announce public healing events, such as prayer services, memorial concerts, or vigils, and make known municipal-sponsored community rituals for mourning, such as a remembrance book displayed at city hall for individuals to sign. There was also the suggestion that the trauma team could act as a clearinghouse for suggestions from the public regarding any additional proposals that might serve to promote healing positively. In addition, municipalities could provide a variety of approved public expressions of remembrance (such as tree planting or setting up memorial park benches).

Participants believed that an appropriate display of grief leadership, behaviours and statements by key leaders that serve to facilitate healthy coping with loss (Fein \& Isaacson, 2009), is an essential civic role. In confronting grief associated with community trauma, effective grief leaders can unify a community in mourning, appropriately guide people in ways of coping, and be symbolic representations of stability and direction.

\section{Creation of Safe Dialogic Spaces}

The second most common theme was the creation of dialogic spaces by municipal officials and other leaders for people to gather, mourn, share experiences, and reconnect. An important part of the communal healing process is having one's story validated and made part of the collective story. Participants proposed a variety of different kinds of spaces that corresponded to the needs of community members. From publiclysponsored sharing circles, to school-based gatherings and family-friendly neighbourhood suppers, many opportunities for healing conversations and authentic connections should be offered to the community in a space that encourages the acceptance of diversity, fosters participation and trust, and cultivates respectful listening. Support materials, such as family discussion guides, could be borrowed from local libraries to be used by parents with their children. In cases of gendered or gang violence, facilitated discussion groups for men, women, youth, or other fol $x^{2}$ directly affected by the trauma could be continually sponsored. As well, participants recommended the creation of a permanent curated space where archived materials that documented people's experiences could be stored. 


\section{Local Leadership Initiatives}

Local leaders have the potential to play a critical role in the recovery of communities after trauma. Every day they hear about how their friends, neighbours, and coworkers are doing, and understand the current emotions and needs of the people with whom they have direct contact. From instituting check-ins with employees or association members to see how people are doing, to sponsoring social activism projects to address the root cause of the trauma (like, for instance, lobbying for stricter gun regulations), local leaders can lead the community in recovery. Additionally, leaders can nurture and model the use of restorative practices and values that inspire healing, transformation, and empowerment (Wachtel \& McCold, 2004) in their organisational milieus. As well as creating ripples of wellbeing, cooperation, and positive social connections that extend out to the community, the use of restorative approaches builds community capacity.

\section{Alternative Methods of Healing}

Participants advised that many non-stigmatising alternative methods of healing be available to community members. Many of these fell into the realm of expressive creative arts like the use of art, music, dance/movement, drama and playbuilding, poetry, and creative writing to process the trauma. The arts have been shown to be an effective tool in processing adversity, both in therapeutic and nontherapeutic contexts (Kuriansky, 2012; Mapp \& Koch, 2004). Since art-making is a basic human behaviour (Dissanayake, 1995), it can provide individuals facing trauma with the opportunity for self-discovery and empowerment, and a context for meaning making through the creative process, as well as helping them develop new ways of expressing emotions, reduce anxiety and fatigue, increase emotional well-being, and support communication with family and friends.

\section{Support from Outside the Community}

The final theme concerned how doing good in ways big or small, not only feels good, but also does one good. Although affected communities can be overwhelmed with outsiders who undermine or marginalise local sources of support, members of neighbouring communities can lend a hand by offering secondary mutual support to combat compassion fatigue, the cost of caring for others in emotional pain (Figley, 1995), and 
burnout for those living, working, and leading in the affected community. Supporting others is exhausting and depleting work, so those who are leading healing efforts in the traumatised community need respite and care themselves. It also affords affected communities the opportunity to pay it forward, to be able to respond to one community's kindness by being kind to another community, lending their hard-won experience in the process.

\section{Conclusion}

This use of readers' theatre was a powerful tool for social engagement and municipal policy development. It successfully outlined community healing strategies crystallised around these five main themes from the point of view of residents. These strategies can foster community-wide posttraumatic growth from collective trauma. This growth could be seen in a transformed identity, as in We are survivors-thrivers, and an increase in the community's social capital, its resilience and generative coping mechanisms, and its capacity for hope in order to overcome adversity and to prevail with increased resources, support, competence, and connectedness.

\section{Notes}

1 There is a vast body of literature that documents this trend. See Belliveau and Nichols (2017), Deloney and Graham (2003), Feldman et al. (2013), Hundt et al. (2010), and Nisker at al. (2006).

2 Folx, an alternative spelling of the word folks, specifically includes and highlights LGBTQ2+, gender non-conforming, and non-binary people thus acknowledging the violence perpetrated towards these communities.

\section{References}

Belliveau, G. (2015). Research-based theatre and a/r/tography: Exploring artsbased educational research methodologies. $p-e-r-f-o-r-m-a-n-c-e, 2(1-2)$. Retrieved from http://p-e-r-f-o-r-m-a-n-c-e.org/?p=1491

Belliveau, G., \& Nichols, J. (2017). Audience responses to Contact!Unload: A Canadian research-based play about returning military veterans. Cogent Arts \& Humanities, 4(1), art. 1351704. https://doi.org/10.1080/23311983.2017.1351704 
Bleuer, J., Chin, M., \& Sakamoto, I. (2018). Why theatre-based research works? Psychological theories from behind the curtain. Qualitative Research in Psychology, 15(2-3), 395-411. https://doi.org/10.1080/14780887.2018.1430734

Calhoun, L., \& Tedeschi, R. (Eds.). (2006). Handbook of posttraumatic growth: Research and practice. Mahwah, NJ: Erlbaum.

Deloney, L., \& Graham, C. (2003). Developments: Wit: Using drama to teach first-year medical students about empathy and compassion. Teaching and Learning in Medicine, 15, 247-251. https://doi.org/10.1207/S15328015TLM1504_06

Dissanayake, E. (1995). Homo aestheticus. Seattle, WA: University of Washington Press.

Donmoyer, R., \& Donmoyer, J. (2008). Readers' theater as a data display strategy. In J.G. Knowles \& A. Cole (Eds.), Handbook of the arts in qualitative research: Perspectives, methodologies, examples, and issues (pp. 209-224). Los Angeles, CA: Sage.

Erikson, K. (1976). Disaster at Buffalo Creek: Loss of communality at Buffalo Creek. American Journal of Psychiatry, 133, 302-305.

Fein, A., \& Isaacson, N. (2009). Echoes of Columbine: The emotion work of leaders in school shooting sites. American Behavioral Scientist, 52(9), 13271346. https://doi.org/10.1177/0002764209332549

Feldman, S., Hopgood, A., \& Dickins, M. (2013). Translating research findings into community based theatre: More than a dead man's wife. Journal of Aging Studies, 27(4), 476-486.

http://dx.doi.org/10.1016/j.jaging.2013.03.007

Figley, C. (1995). Compassion fatigue as a secondary traumatic stress disorder: An overview. In C. Figley (Ed.), Compassion fatigue: Coping with secondary stress disorder in those who treat the traumatized (pp. 1-20). New York, NY: Brunner Mazel.

Hundt, G., Bryanston, C., Lowe, P., Cross, S., Sandall, J., \& Spencer, K. (2010). Inside 'Inside View': Reflections on stimulating debate and engagement through a multimedia live theatre production on the dilemmas and issues of pre-natal screening policy and practice. Health Expectations, 14, 1-9. https://doi:10.1111/j.1369-7625.2010.00597.x

Kaufman, M., and members of the Tectonic Theatre project. (2001). The Laramie project. New York, NY: Vintage.

Krueger, R., \& Casey, M. A. (2009). Focus groups: A practical guide for applied research (4th ed.). Thousand Oaks, CA: Sage.

Kuriansky, J. (2012). Our communities: Healing after environmental disasters. In D. Nemeth, R. Hamilton, \& J. Kuriansky (Eds.), Living in an environmentally 
traumatized world: Healing ourselves and our planet (pp. 141-167). Oxford, UK: Praeger.

Manyena, S., O'Brien, G., O'Keefe, P., \& Rose, J. (2011). Disaster resilience: A bounce back or bounce forward ability? Local Environment, 16, 417-424. https://doi.org/10.1080/13549839.2011.583049

Mapp, I., \& Koch, D. (2004). Creation of a group mural to promote healing following a mass trauma. In N. Webb (Ed.), Mass trauma and violence (pp. 100-119). New York, NY: Guilford Press.

Nisker, J., Martin, D., Bluhma, R., \& Daar, A. (2006). Theatre as a public engagement tool for health-policy development. Health Policy, 78, 258-271. https://doi:10.1016/j.healthpol.2005.10.009

Raphael, B. (1986). When disaster strikes: How individuals and communities cope with catastrophe. New York, NY: Basic Books.

Reilly, R. C. (2011). "We knew her..." Murder in a small town: A hybrid work in three voices. Qualitative Inquiry, 17(7), 599-601. https://doi:10.1177/1077800411413997

Saldaña, J. (1998). Ethical issues in an ethnographic performance text: The "dramatic impact" of "juicy stuff". Research in Drama Education, 3(2), 181196. https://doi.org/10.1080/1356978980030205

Wachtel, T., \& McCold, P. (2004, August). From restorative justice to restorative practices: Expanding the paradigm. Paper presented at the 5th International Conference on Conferencing and Circles, Vancouver, BC, Canada. 